\title{
A device for presenting attack opportunity as a reinforcer for operant behavior
}

\author{
JAMES L. CONNOR and PATRICE WATSON \\ University of Nebraska-Lincoln, Lincoln, Nebraska 68588
}

\begin{abstract}
A device is described which automatically measures barpresses reinforced by short opportunities to attack male mice. Data on barpress rates indicate rapid and reliable acquisition of preferences for reinforcer bars and rapid abolition of this preference when the reinforcement contingency is subsequently eliminated. The data are less reliable for reversal learning.
\end{abstract}

Animal aggression consists of several separate categories of behaviors which involve physical attack but differ considerably in their stimulus elicitation and/or pattern of motor movement (Moyer, 1968; Tinbergen, 1953). Several of these types can also act as reinforcers: Aversive aggression is elicited by painful electric shock (Azrin, Hutchinson, \& McLaughlin, 1965; Dreyer \& Church, 1970); predatory aggression is elicited by an animal of a different species (Van Hemel, 1972); territorial display is elicited by miror images or visual models (Hogan, 1967; Melvin \& Anson, 1969; Thompson \& Sturm, 1965); and intermale aggression is elicited by an attackable male of the same species (Legrand 1970; Tellegen \& Horn, 1972; Tellegen, Horn \& Legrand, 1969).

In spite of a substantial and growing literature, it is difficult to find a fully automated method for measuring the reinforcing effects of intermale conspecific aggression, a form of fighting extensively analyzed in ethological and genetic studies (Connor, 1975; Scott, 1966; Tinbergen, 1953). With intermale aggression, it is difficult to provide reinforcement automatically because the method requires the intruder to be presented and subsequently removed in a way that is nonpunitive to the aggressor. In the predatory situation the intruder may be removed by being consumed. With the display method the visual image may be removed by eliminating the source of light.

In the interanimal situation, the intruder in alleyway and maze studies is typically removed by physically separating the opponents and subsequently lifting the victim out by the tail (Legrand, 1970; Tellegen \& Horn, 1972; Tellegen et al., 1969). This step introduces a potential source of experimenter bias, interrupts operant responding, and necessitates constant human observation during testing.

This research was assisted by funds from NIH Biomedical Sciences Support Grant RR-07055-09 (University of Nebraska). Requests for reprints should be addressed to: Dr. James Connor, Department of Psychology, 209 Burnett Hall, University of Nebraska-Lincoln, Lincoln, Nebraska 68588.
This paper describes a device that overcomes the problem of intruder delivery/removal in the assessment of aggression reinforcement. The operant behavior occurs in a familiar home cage in which the animal is untouched by the experimenter prior to, during, or after testing.

\section{METHOD}

\section{Subjects}

The subjects were three male mice drawn from a breeding stock of wild mice described by Connor (1975). Animals were approximately 90 days old at the start of testing.

\section{Apparatus ${ }^{1}$}

The apparatus consists of a mouse cage/Skinner box and an intruder delivery system (see Figure 1). The Skinner box is $31 \times 31 \times 31 \mathrm{~cm}$ and made of Plexiglas; normally a clear Plexiglas lid covers the top of the box. During testing, the intruder delivery system replaces the lid and the two retractable bars are slid into the box. The retractable bars are $6 \times 12 \mathrm{~cm}$ pieces of sheetmetal mounted in holders bolted to the outside of the cage (see Figure 1). The holder provides a fulcrum for each bar, and contains two plastic slots from Series 200 Digibit circuit boards serving as tracks. These allow the bar to be moved to one of two extreme positions: retracted, so that the bar rests entirely outside the box, or inserted, so that the bar projects into the cage. The distal end of each bar contains a screw upon which counterweights can be attached and electrical contacts that record barpress closures. The common contact is an electrically insulated point attached to the bar. The normally open contact is a metal strip suspended above the common and attached to the stationary holder. The normally closed is similarly attached but beneath the common. Careful counterweighting is required, since the weight of a $20 \mathrm{~g}$ mouse must produce closure of the normally open circuit when the mouse releases the bar.

The intruder delivery system (Figure 1) consists of a $30-\mathrm{cm}$ high Plexiglas tube (2) with an inside diameter of $6.4 \mathrm{~cm}$. The intruder is suspended inside the tube by braided nylon fishing cord. This cord is released or taken up by means of a large 27.5 -cm-diam plastic wheel (3) with a $2-\mathrm{cm}$-deep groove. The weight of the mouse causes a strain on the reversible motor (4) which is relieved by means of a counterweight (5) that is dropped when the intruder is lifted and raised when the intruder is dropped. The distance that the intruder is dropped is controlled by a DOWN microswitch (6) that is tripped by a cam attached to the wheel axle. The cam's position on the axle is adjusted by screwing down a hex nut which locks the cam onto the wheel axle. The total length that the intruder is lifted is controlled by a second UP microswitch (6) that is tripped by a 


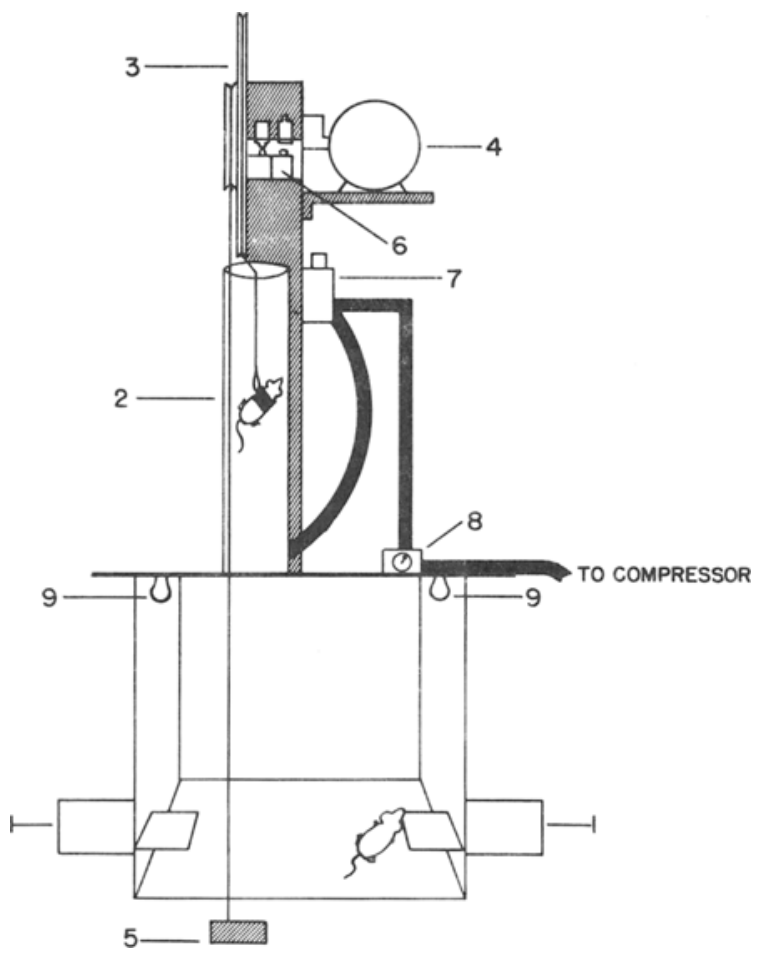

Figure 1. Mechanical design of aggressive reinforcement device.

second adjustable cam. The UP cam is set approximately $90 \mathrm{deg}$ to the DOWN cam. The maximum distance that the intruder can be dropped and lifted is $80 \mathrm{~cm}$.

The intruder is attached by a safety pin to a washer tied at the end of the fishing cord. The safety pin is attached to the intruder by means of a harness made of electrical tape and a small washer. (The electrical tape is wrapped around the mouse's rib cage; the washer provides reinforcement for a flap made in the back where the pin is attached.)

In operation, a fixed number of barpresses activates the motor (4) that turns the wheel in a counterclockwise direction, thus dropping the intruder. The counterclockwise movement continues until the motor control relay is unlocked by the UP microswitch. Reinforcement delivery is recorded electrically as the interval between the operation of the DOWN microswitch and the initiation of timer output.

Several options are included in the system. Two light sockets (9), built into the reinforcement delivery system, can be used as a signal (discriminative stimulus) for the availability of reinforcement upon pressing a given bar. Also, during development of the system we observed that the aggressor occasionally bit and seized the intruder. As a result, the aggressor was carried up along with the victim into the tube (2). This problem was overcome by a solenoid-operated air valve (7) that operates when the motor turns during the UP cycle. This valve passes air into the neck of the tube by means of two needle valves mounted at a 160 -deg angle. The size of the hole drilled into the plastic cylinder must be small $(.5 \mathrm{~cm})$ to discourage the intruder from breaking his fall by inserting a paw into the hole. The valves are mounted so that they are directed at the lip of the tube and not directly into the aggressor's cage. The pressure of the airblast is regulated from 100 to 0 psi by means of a pressure guage (8) mounted between the air valve ( 7$)$ and a compressor, providing compressed air at $100 \mathrm{psi}$. In operation, the lip of the tube serves as a baffle and the aggressor encounters significant turbulence only when he enters the tube. Subjects have shown no tendency to hold onto the intruder to be carried up into the tube. (The airblast option was not used in the study reported here.)

Electrical design of the control circuit is illustrated in Figure 2. Barpress closure operates an event-recorder pen that measures time on the bar. Barpresses are also input into the reinforcement delivery mechanism. Essentially, the circuit controls delivery of ac line 1 current into a reversible motor with ac line 2 being permanently connected into the common of the motor. The ac 1 into the top motor lead results in a counterclockwise DOWN movement; ac 1 into the bottom motor lead results in a clockwise UP movement.

\section{Procedure}

The test males (TM) were housed in the apparatus/home cage for 1 week prior to testing. After this adaptation period, the TM encountered a nonaggressive $\mathbf{A} / \mathrm{J}$ male intruder lowered into the home cage for $5 \mathrm{~min}$ on 1 day. On the following day, the TM encountered the intruder during 20 successive 5 -sec presentation periods separated by a 30 -sec interpresentation interval. During the next 3 days (Operant Level Sessions 1, 2, and 3 ), the TM received five free 5 -sec attack opportunities separated by 1 -min intervals. At the end of this 4 -min 25 -sec session, the intruder was raised into the tube above the home cage and the two bars were inserted into the home cage for $15 \mathrm{~min}$. Operant level was measured for the TM's nonreinforced barpressing rate once daily for 3 successive days.

Essentially, the research plan after operant level testing followed an A-B-A within-subjects design. During Phase A (acquisition sessions), acquisition reinforcement was contingent on pressing Bar B. During Phase B (noncontingency sessions) reinforcement was delivered noncontingently with barpressing. During the subsequent Phase A (reversal sessions), reversal reinforcement contingency was reestablished and was dependent on pressing Bar $\mathrm{A}$.

After three days, the operant level/free attack sessions were terminated and a reinforcement schedule instituted. On Acquisition Session 1 pressing Bar B produced a $1-\mathrm{sec}$ intruder presentation on a continuous reinforcement schedule. On Acquisition Sessions 2-8, the response requirements were increased to fixed ratio 30 . Daily sessions on Acquisition Sessions 2-8 lasted until the completion of five reinforcement deliveries. The 8 -day period of acquisition sessions (Phase A) ended after barpress rates had stabilized. The criterion for stability was 3 successive days during which the daily operant rates varied no more than $\pm 10 \%$ from the mean of the 3 days. During the next 6 -day noncontingency sessions (Phase B), the reinforcement schedule was based on the delivery times during the prior six sessions of pretesting. The TM was presented with the two bars, but reinforcement delivery was determined solely by delivery times on one of the previous (Phase A) sessions. The delivery schedules on the prior 6 days (Phase A) were sampled randomly without replacement so that, at the end of the 6-day Phase B period, all six of the delivery schedules had been used exactly once. At the end of the Phase $B$ noncontingent period, a contingent FR 30 schedule was reinstituted. Reinforcement delivery was dependent on pressing Bar A during these reversal sessions; delivery had been dependent on pressing Bar B during the acquisition period. Reversal sessions continued until baselines stabilized.

\section{RESULTS AND DISCUSSION}

Daily barpress rates for two subjects (see Figure 3) yielded stable responding over sessions and fair sensitivity to manipulations of reinforcement contingencies. During acquisition, presentation of attack opportunities 


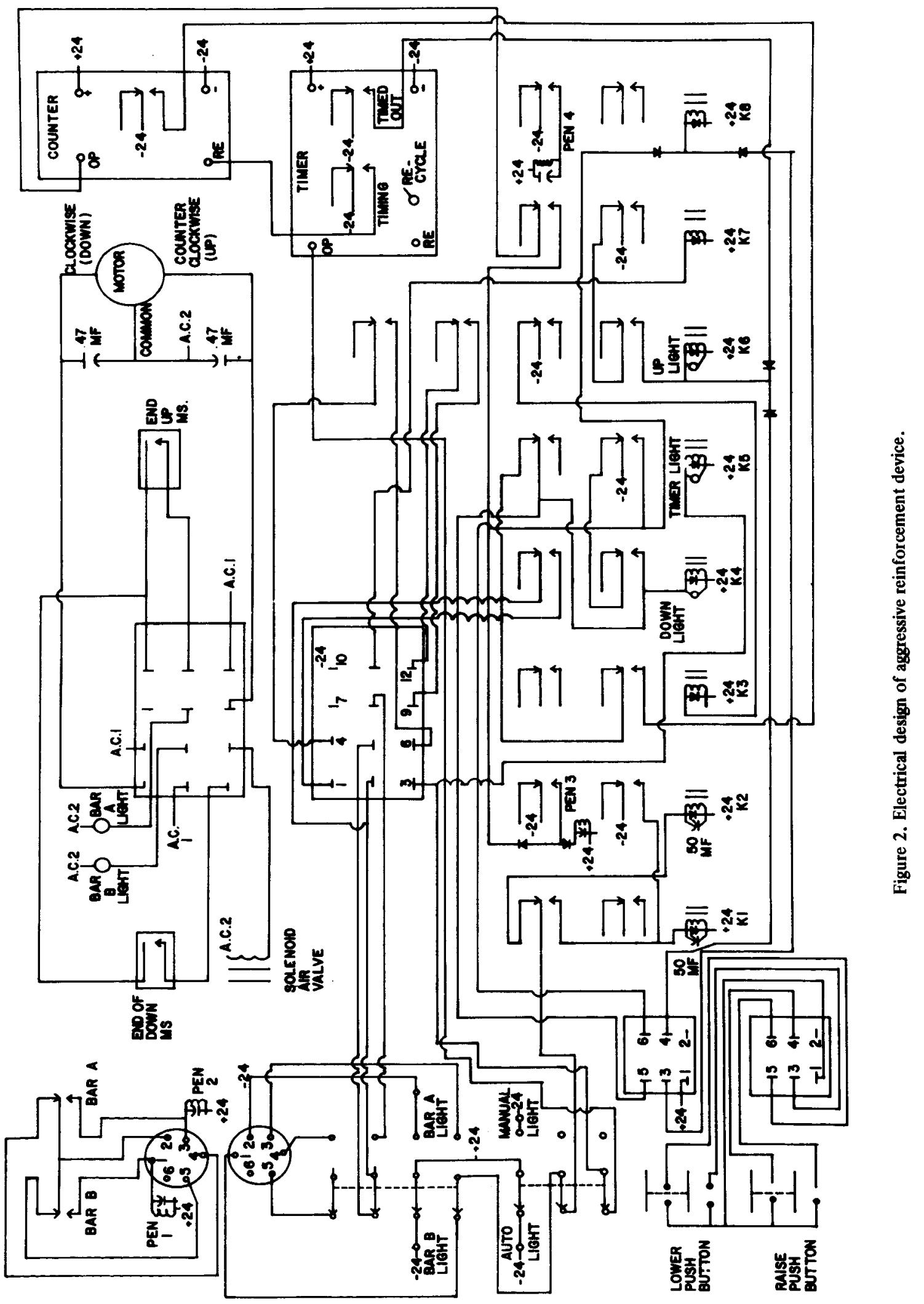


contingent on pressing Bar B elevated barpress rate to a level several times greater than that obtained on the nonreinforced Bar A. During noncontingency sessions, elimination of the reinforcement contingency with Bar B eliminated the difference in Bar B vs. Bar A baselines. Thus, most baseline elevation obtained on Bar $B$ in acquisition was due to the contingency of aggression with barpressing. Comparison of the nonreinforced operant level sessions with the noncontingency sessions (Figure 3 ) suggests some elevation due to activity induced by reinforcement presentation per se.

During reversal sessions, reinstitution of a contingency involving the previously nonreinforced bar reestablished operant performance in only one of the three mice. The data from this mouse and from one of the failures are included in Figure 3. The reversal period of the failures was continued for 16 days. (Data in the figure represent every second day.) Failures continued to respond at a low rate, but they continued to attack the intruder whenever a reinforcement was delivered. Both failures showed successful learning during earlier acquisition sessions.

The apparatus described in this paper has several advantages over $\mathrm{T}$-maze and alleyway methods of assessing aggressive reinforcement: (1) greater reliability, (2) elimination of the requirement that the experimenter be in continual attendance, (3) capability of measuring operant behavior in an undisturbed home cage environment familiar to the animal, and (4) ability to test either single response-reinforcer contingencies (like alleyways) or multiple response-reinforcer con-

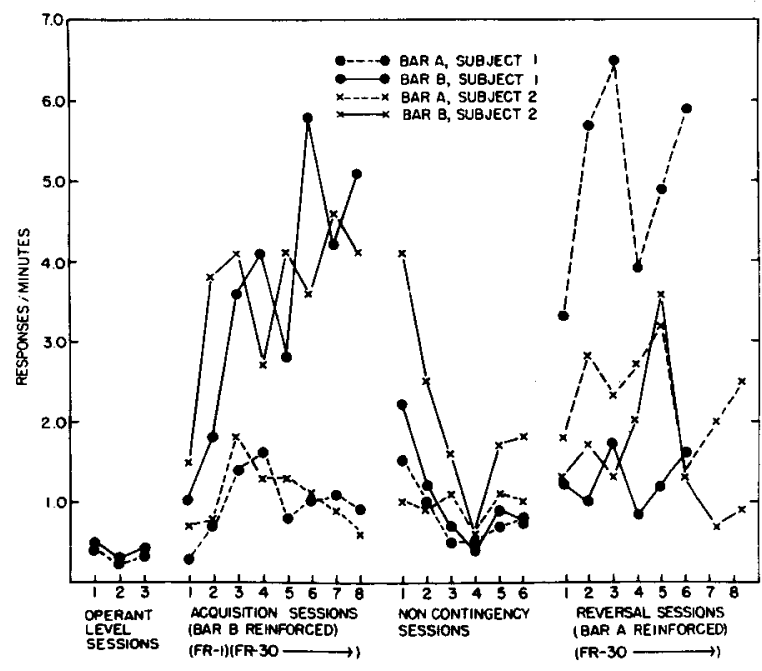

Figure 3. Barpress rates for acquisition, noncontingency, and reversal sessions. tingencies (like $T$-maze preference) in the same apparatus.

\section{REFERENCES}

AzRin, N. H., Hutchinson, R. R., \& Mclaughlin, R. The opportunity for aggression as an operant reinforcer during aversive stimulation. Journal of the Experimental Analysis of Behavior, 1965, 8, 171-180.

Connor, J. Genetic mechanisms controlling the domestication of a wild housemouse population. Journal of Comparative and Physiological Psychology, 1975, 89, 118-130.

DReYer, P. I., \& ChURCh, R. M. Reinforcement of shockinduced fighting. Psychonomic Science, 1970, 18, 147-148.

Hogan, J. A. Fighting and reinforcement in the Siamese fighting fish (Betta splendens). Journal of Comparative and Physiological Psychology, 1967, 64, 356-359.

LEGRAND, R. Successful aggression as the reinforcer for runway behavior of mice. Psychonomic Science, 1970, 20, 303-305.

Melvin, K. B., \& Anson, J. E. Facilitative effects of punishment on aggressive behavior in the Siamese fighting fish. Psychonomic Science, 1969, 14, 89-90.

MOYER, K. E. Kinds of aggression and their physiological basis. Communications in Behavioral Biology, Part A, $1968,2,65-87$.

Scotr, J. P. Agonistic behavior of mice and rats: A review. American Zoologist, 1966, 6, 683-701.

Tellegen, A., \& Horn, J. Primary aggressive motivation in three inbred strains of mice. Joumal of Comparative and Physiological Psychology, 1972, 78, 297-304.

Tellegen, A., Horn, J. M., \& Legrand, R. G. Opportunity for aggression as a reinforcer in mice. Psychonomic Science, 1969, 14, 104-105.

Thompson, T., \& STURM, T. Visual-reinforcers, color, and operant behavior in Siamese fighting fish. Joumal of the Experimental Analysis of Behavior, 1965, 8, 341-344.

TINB ERgen, N. Social behavior in animals. London: Chapman \& Hall, 1953. Pp. 57-72.

Van Hemel, P. E. Aggression as a reinforcer: Operant behavior in the mouse-killing rat. Journal of the Experimental Analysis of Behavior, 1972, 17, 237-245.

\section{NOTE}

1. The following commercially available parts were used in the construction of the device: (1) Air compressor, 3/4 HP, No. 408, E. L. Smith \& Sons, Quincy, Illinois. (2) Skinner solenoid-operated air valve (Army surplus item), No. 20-02, obtainable from Surplus Center, Inc., Lincoln, Nebraska. (3) Electronic timer, No. T1-903, BRS/LVE. (4) Predetermining counter, No. PC-903-2431-15, BRS/LVE. (5) Reversible motor, $3 \mathrm{rpm}$, Type VIOR, Bodine Corporation, Chicago, Illinois. (6) Air-pressure regulator with gauge (range 0 to $100 \mathrm{psi}$ ), Wilkinson Corporation, Englewood, Colorado.

(Received for publication February 3, 1977; revision accepted April 6, 1977.) 